\title{
A Steady Pulse: Restaging Lucinda Childs, 1963-78, The Pew Center for Arts and Heritage, 2015, Online publication http://pcah.us/asteadypulse
}

Marie-Louise Crawley, C-DaRE (Centre for Dance Research), Coventry University

Keywords: Lucinda Childs, The Pew Center for Art and Heritage, danceworkbook, archive

A Steady Pulse: Restaging Lucinda Childs, 1963-78 is the fourth publication in The Pew Center for Art and Heritage's online danceworkbook series. The series aims to interrogate and document creative practices in dance and, as part of the Center's wider research remit, to engage practitioners in a vibrant exchange of ideas concerning these practices. It has previously explored the artistic processes of Headlong Dance Theater's collaboration with choreographer Tere O'Connor, the work of contemporary dance artist Roko Kawai, and three of dance scholar Susan Leigh Foster's performed lectures. A Steady Pulse explores and re-examines Lucinda Childs' "dances in silence," specifically eight works spanning 1963-1978: Pastime (1963), Street Dance (1964), Museum Piece (1965), Reclining Rondo (1975), Radial Courses (1976), Melody Excerpt (1977), Interior Drama (1977) and Katema (1978).

The online workbook, beautifully designed by Andrew LeClair and Adam Lucas, couples video documentation of these eight early works, re-performed in Philadelphia and Bronxville, New York between 2009 and 2013, with a selection of critical texts. These essays explore the importance of the original "dances in silence" in terms of forging Childs' distinctive compositional voice (especially post-Judson), as well as offer approaches to possible restagings and reconstructions of these historic dance works. Two of the main texts are written by Childs, with another by her artistic associate Ty Boomershine. The central essay in the collection, "The Art of Refusal: Lucinda Childs' Dances in Silence, 1973-78" is by dance historian Suzanne Carbonneau. The rich combination of these three voices is a fitting demonstration of the ways in which this project situates itself at the fruitful intersection of scholarship and practice. The publication also includes an extensive collection of photographs, program notes, and other ephemera, most of which originate from Childs' own personal archive. There are also several of Childs' own scores, including one (the 158-page score for Melody Excerpt) that is fully digitally animated by Jorge Cousineau. Here, the complex choreographic patterns and pathways that are drawn on the visual scores are animated in real time before the viewer's eyes. Childs' visual scores, so important to 
her practice in in terms of creating the architecture of the piece, as well as in establishing the relationship of dancers to one another, are quite literally brought to life both through digital animation and through the video recordings of the reworked dances; that the online platform enables the juxtaposed viewing of these features is both appropriate and exciting.

As the introduction to the publication outlines, this particular danceworkbook is timely not only because it feeds into an essential part of the Center's wider ongoing research into trans-disciplinary artistic practices and processes, but also because it is directly concerned with important questions regarding the matters of the reconstruction, restaging, and re-enactment of historic dance works. Through its online format, the workbook proposes an exciting response to pressing questions, including how we archive dance, and how the past history of a dance work both intersects with its present and points towards its future. As the Center's Director of Performance, Bill Bissell, explained at the launch of the publication in 2015, "Lucinda's is a living archive and we have tried to make that the case in the workbook." 1 The archive is "living" because it is concerned with how dance works are transmitted across generations through the act of dancing. The workbook, precisely because of its focus on the act of recovering dances of the past in the present, in turn itself becomes a living, transmitting archive of these eight works. The flexibility of the online platform means that the viewer-reader can navigate across multiple temporalities with ease: we can watch a re-working of a dance in 2013, then immediately cross-reference it with the "original" score and with photographs or, in the case of Katema for example, with a video recording of the "original" presentation of the work from 1978. The viewerreader is also free to choose the order in which he/she views both the works and their related artifacts so that both chronological and non-linear viewings are possible. The multiplicity of viewing/reading options in itself opens up multiple possibilities for understanding how past works are re-constructed in the present and what those acts of reconstruction entail.

It is important to stress the central role that Childs herself has played in the development of this project. Childs was a driving force behind the reconstructions featured and she remained an essential collaborator throughout the Center's process of finding an innovative way to preserve and disseminate her personal archive. In fact, one of the main strengths of the workbook is the manner in which it has been developed with Childs in this extremely personal way. What is perhaps most striking throughout the workbook is the way in which the voice of Childs' practice speaks loud and clear and is in fact central to the whole archival endeavor. These dances are perhaps not so silent after all.

For this reader-viewer, two of the most striking "artifacts" in this archive are the videotaped readings by Steve Paxton and Yvonne Rainer of letters they wrote to Childs in 1964 and 1968 respectively. Just as the reworked dances (and, of course, the 
dancers involved in both the originals and in the reworkings) are living archives of the work itself, with these two video-recorded readings, the archive literally comes to life before the viewer's eyes. What we might hold in our hands in a traditional archive - a typewritten or handwritten letter from the past - we are able to witness here read aloud by its author in the present (with all the reflexivity embedded in a moment when an author looks back on a past act of writing in the present act of reading). This is more than a touch of the personal; it is yet another layer added to the complex and various temporal strata at play in the archive.

With this publication, the Center's hope is that "in addition to serving as a valuable resource for future scholars of postmodern dance, A Steady Pulse will contribute significantly to the ongoing dialogue around how we, as a society, value and preserve [dance and cultural history]."2 With its successful intersection of the voices of practice and scholarship, as well as (and indeed because of) the flexibility and accessibility of its format, A Steady Pulse: Restaging Lucinda Childs, 1963-78 certainly fulfills this hope. It also continues to open the way for other archival projects to test out innovative ways in which online and other non-traditional archives might enable us to continue probing those essential questions, asking how we rework dances and how we preserve our wider dance and cultural history.

\section{Biography}

Educated at the University of Oxford (B.A. Hons, M.St.) and trained at the Ecole Marceau in Paris, Marie-Louise began her professional performance career with Ariane Mnouchkine's Theatre du Soleil (2003-2009). Since 2010, she has been working in the UK as an independent choreographer and dance artist with companies as diverse as Birmingham Opera Company, Marc Brew, Gary Clarke, Ballet Cymru and Rosie Kay Dance Company. Recent new work has included pieces for a TATE / ARTIST ROOMS exhibit and for the Ashmolean Museum, Oxford. She is currently Artist-in-Residence at the Archive of Performances of Greek and Roman Drama, University of Oxford. MarieLouise is a PhD candidate at C-DaRE, Coventry University (UK), researching dance in the museum.

Email: crawleym@uni.coventry.ac.uk 


\section{Notes}

1 "The Making of A Steady Pulse," https://vimeo.com/129137453

2 A Steady Pulse: Restaging Lucinda Childs,

http://danceworkbook.pcah.us/asteadypulse/about.html

\section{References}

"The Making of A Steady Pulse: Restaging Lucinda Childs, 1963-78 Part 1" (2015). Prod.

The Pew Center for Arts and Heritage. Vimeo. Accessed 27 Jan 2017.

https://vimeo.com/129137453

A Steady Pulse: Restaging Lucinda Childs, 1963-78. Danceworkbook. The Pew Center For Arts and Heritage. Accessed 27 Jan 2017

http://danceworkbook.pcah.us/asteadypulse/about.html 